\title{
APPLICATIONS OF INTEGRATED SURVEY FOR HISTORICAL HERITAGE'S KNOWLEDGE: DIGITAL MODELING OF THE VILLA RUFOLO'S MOORISH CLOISTER IN RAVELLO
}

\author{
V. Iannizzaro ${ }^{\text {a }}$ B. Messina ${ }^{\mathrm{b}, *}$, M.R.Cundari ${ }^{\mathrm{c}}$ \\ Department of Civil Engineering, University of Salerno, Italy \\ av.iannizzaro@unisa.it - ${ }^{\mathrm{b}}$ bmessina@unisa.it - ${ }^{\mathrm{c}}$ mcundari@unisa.it
}

KEY WORDS: Amalfi coast, 3D laser scanning, digital anastylosis, Islamic influences, geometric composition

\begin{abstract}
:
Within a more general research topic, with reference to the possibilities offered by new technologies in terms of documentation and knowledge of the historical architectural heritage, it is interesting to test the utility of a congruent use of several detection techniques; and is not meant as pure addition but as integration of systems, to each other complementary. With specific reference to the survey's techniques, analyzing for each methodology the definition of general and specific checking's procedures of the results' correctness, we intend to test the possibility of an integrated use of these, especially in complex architectures. An interesting field of application of the proposed methodology was the cloister of Villa Rufolo in Ravello, in Amalfi Coast, in which fragments of the past, more or less intact, coexist along with structures built in later periods. Here, various survey's methods have been applied - topographic, photogrammetric, laser scanners - each in reference to their own specificities. The obtained data from each application were then correlated, thanks to the presence of a points' network that allow the integration of information, at first separately processed.

The $3 \mathrm{~d}$ model, generated by the union of each processed part, was then the starting point for the elaboration of an infographic space that is an important step of documentation. In fact, critically interpreting the previously acquired data, we can imagine to make accessible, albeit virtually, the lost space, digitally reconstructing its original architectural shapes.

The research has led to particularly significant outcomes, in terms of techniques' integration and, also, validation of each used method for the digital documentation.
\end{abstract}

\section{INTRODUCTION ${ }^{\mathrm{b}}$}

\subsection{The employed methodology}

The work that the present paper summarizes, expresses the results of a wider research conducted within the $\mathrm{PhD}$ in Structural Engineering and Building and Urban Rehabilitation, active in the Engineering Faculty of the Salerno's University, in Italy. In particular, the research entitled Integrated Surveys of architectural heritage. The laser scans and the digital processing (PHD Maria Rosaria Cundari; tutor prof. Vincenzo Iannizzaro; cotutor prof. Barbara Messina), addressed several particularly relevant issues in the field of representation and documentation of historical built heritage.

The target also has been test the reliability of this procedure with reference to deeply transformed architectural assets, over the centuries. In these cases, in fact, the documentation, firstly but not only metric-formal, forms the starting point for a real knowledge.

Then, recovering - albeit only virtually - shapes and features deduced from experimental data, recorded in the field, it finally becomes possible a space's reading, back in time, through infographic modeling, so returning the original image of the investigated architecture.

\subsection{Represent to get to know}

The knowledge of a context - whether urban or architectural always has as a prerequisite the direct experience of the space that defines it. However, to fully understand the hidden laws of space's phenomenic image, to seize the harmonic structure from which reality takes shape, in the variety of compositional elements, it becomes essential its graphical representation. Representation that, far from being understood as simply metric-formal reading, becomes instead a critical-interpretative act, capable of revealing the innermost relationships that are established between geometrical rigor and free expression of the form. The search for signs of the past, through a reasoned verification, and the graphic study of the single architectural elements, then interpreted as a whole and contextualized in the urban structure to which they belong, are, therefore, essential moments to focus on the specifics of a place.

The built space arises itself as a tangible expression of the transformations produced by the man who, as also observed by Panofsky, "... is the only that leaves testimonies behind it, as it is the only whose artifacts bring to mind a different idea from their material existence" (Panofsky, 1962). Therefore, it is the tangible synthesis of culture and tradition that produced it, diversifying depending on the age as well as the geographical and artistic context in which it was conceived. Then, if you want to achieve its deep knowledge, it is essential decode the complexity of the forms that constitute it, in order to understand its true essence. In this sense a correct cognitive approach can not be limited to mere passive contemplation of the architectural space: its cultural appropriation is inevitably based on strict control of the qualities and values, that emerge from the space's direct experience.

If, therefore, a specific scientific value is attributed to the representation - namely we recognize that it can promote the formulation of critical and analytical methodologies addressed to the analyzed reality's study - we arrive at the interpretation of the drawing as a system with which to define, interpret, and at the same time communicate the built space through graphic

\footnotetext{
* Corresponding author
} 


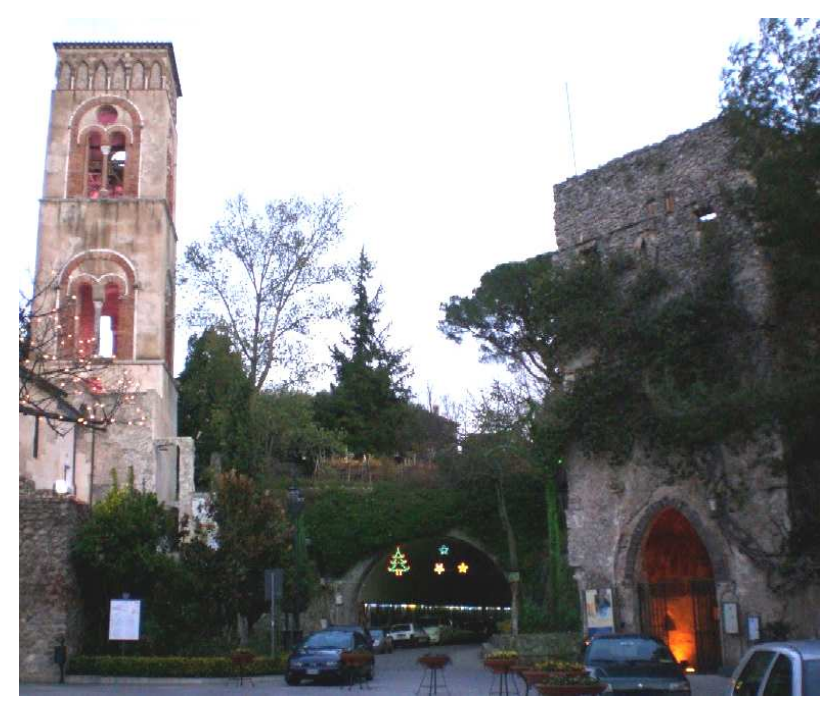

Figure 1. The bell tower and the entrance of Villa Rufolo

works that, by virtue of an inherent objectivity, for example connatural to Descriptive Geometry's methods or to the used conventions, uniquely identify the real data, albeit with due graphical simplifications.

With reference to the historic built heritage, it should be noted that it is a field that requires constant updating in terms of representation's techniques and procedures for storing collected data, especially when you consider that this heritage is typically used every day, as well as subject to continuous transformations, sometimes minimal as a result of the natural time's flow or of the specific use, in others more substantial, because caused by traumatic events, such as wars or earthquakes.

The deep knowledge of a building, in reference to its historical dating, or to the metric-formal aspects, to the state of preservation, to the intended use, can then facilitate the protection and preservation process of the rich architectural heritage, and also allow to recover visual memory of some particularly significant architectural episodes. In this sense, there is a need to develop methods able to outline a specific protocol for the analysis and representation of the built space, identifying the processing suitable for the documentation, the graphical interpretation and for the integrated digital management of collected data. Drawings, therefore, that not only aim to the final product's visual impact, but rather to transmit the complete knowledge of the represented reality, through an information corpus that allows to recognize as own the investigated heritage.

A correct approach to the described problem, thus, requires the adjustment of the so far used methodologies, in general addressed to single aspects of analyzed reality, which is then read in an almost always partial way. So, it seems particularly appropriate the provision of an integrated digital representation system, able to guarantee a rapid spreading and exchange of information about the analyzed buildings. If the inevitable scientific premise is the acquisition of metric-formal data related to the investigated heritage, the documentation of the built space, in the broadest sense, can not be separated, as already noted, from the graphic representation of other information: the hidden geometry, that characterizes the architectural elements specific to a context, the volumes' proportional relationships, between them and with the surrounding environment, the effect produced by the use of

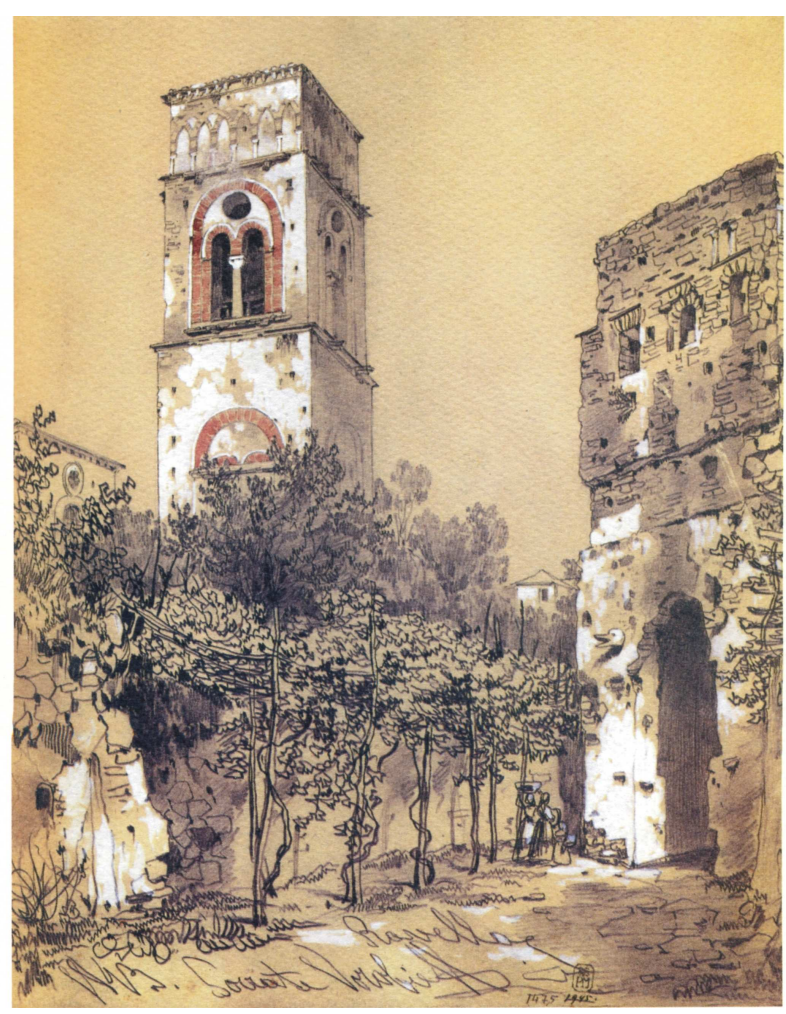

Figure 2. S. M. VOROb'eV, Ravello - watercolor of 1843

certain materials, and also the representation of the immaterial aspects. Meaning by this term less tangible aspects such as the static behavior, the volumes' weight, the answer to certain stress or actions which a building may be subject, until to include the perceptual qualities, related to the viewer's subjective participation to a built space.

If then it is indisputable that the cultural appropriation of the architectural heritage can not be generated only investigating the physical size and the space's morphology, but rather capturing its entirety, its complexity and all its quality, it is helpful to use digital modeling to simulate - with great verisimilitude if appropriate - some architectural space's aspects, difficult to express with the traditional representation, though necessary as the knowledge's initial moment.

\section{EXPERIENCE OF INTEGRATED SURVEY: THE CLOISTER OF VILLA RUFOLO}

The overall objective of the research, created to explore the issues of integration between the various techniques of survey, progressively oriented - based on repeated use of the various techniques and related procedures - to define procedures to help ensure both verify the repeatability of the individual measures and their processing / refunds. In short it is progressively outlined a path operating which could form the basis for a quality certification (as has been regulated in other operating segments and categories) also as part of the architectural survey. The episode architectural chosen for the experimental activities is the small cloister of Arabic influence of Villa Rufolo in Ravello with architectural spaces connected to it.

It required a multiplicity of approaches to the strong differences in morphology and size of its various elements - even medieval architectural invaded by the delicate and minute columns of the 


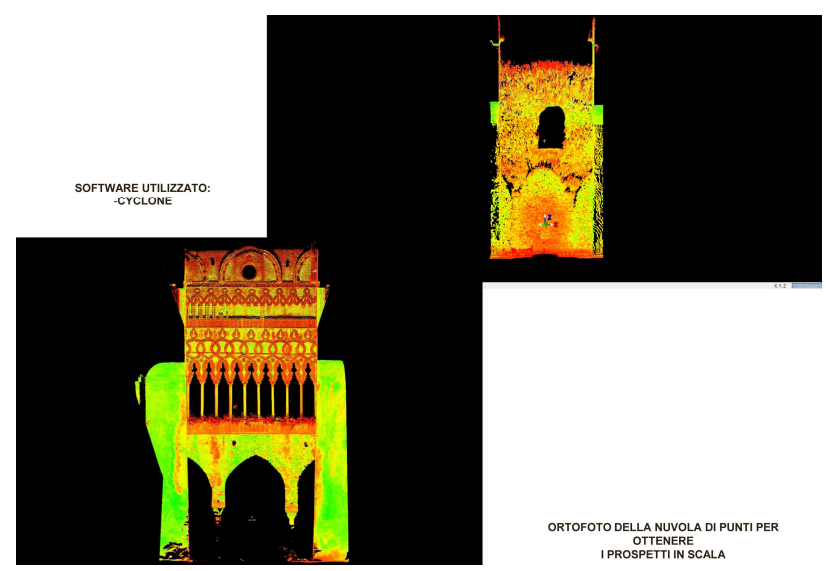

Figure 3. Orthophotos from the point cloud of the cloister

Arab partition wall (with reduced small distance between the columns) - and has involved the use of different techniques and of survey, from time to time, appropriate to the needs, constituting a privileged field of experimentation.

Based on the activities carried out, it is appropriate to outline the procedure that is derived from research, whose main steps can be summarized as follows:

phase I: General inspection and photographic documentation. The object, according to the purpose of the survey is: a) to define the technical of survey use, b) the use to design, c) the design of complex two-and three-dimensional graphics refunds needed for documentation and communication, d) to decide their representation scale (in relation to the characteristics of the various parts of the building), e) to provide for data acquisition campaigns and measures different level of detail to support the various refunds;

phase II: Surveying. The object is to establish a general network of measured points on surfaces (internal and external) of the building, the results of the topographic survey shall include, in addition to the printout of the coordinates of the measured points, monographs and photographic documentation of the individual measured points, both in paper and digital format. The detection must be specifically depth for those parts of the building intended for a representation of greater detail. Particular attention should be paid to the selection of points that are stable (edges of architectural elements, etc.). And easily recognizable in both the digital and photographic documentation in electronic scans;

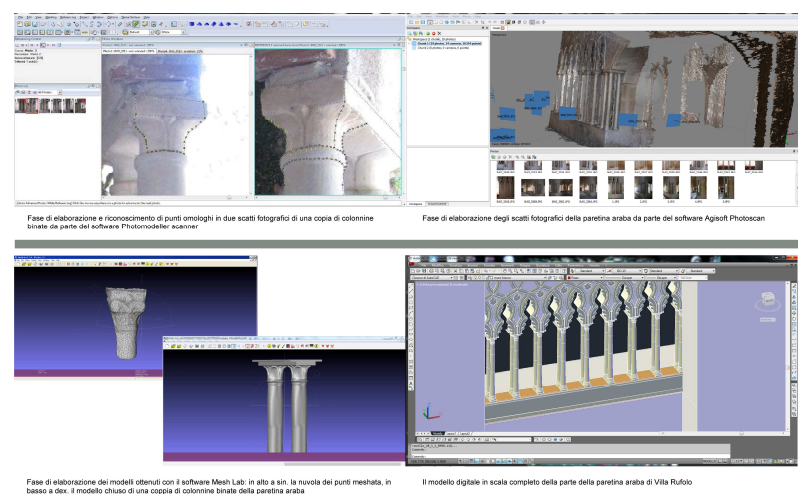

Figure 5. Views from Photogrammetric software for processing

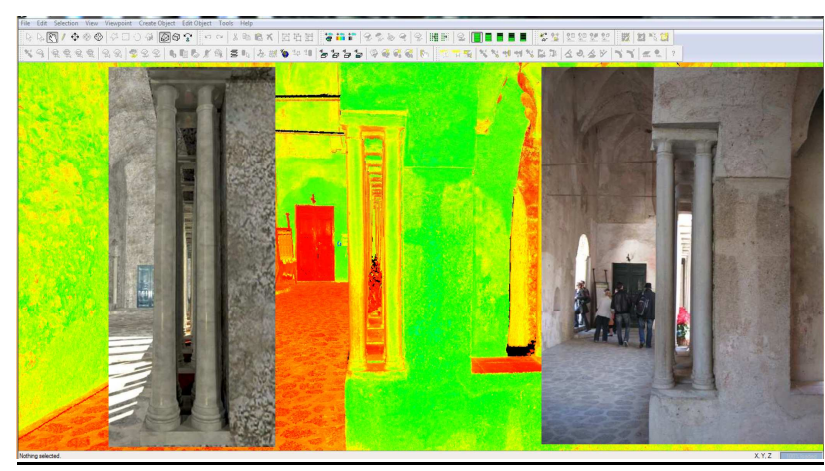

Figure 4. Orthophotos from the point cloud: double columns

phase III: Detection photogrammetry. The technological evolution confirms the usefulness of the technique in the photogrammetric survey, recent systems have revived the principle stereophotogrammetric (also based on the forward intersection) offering dedicated software which reproduce the recurrence of the "normal case" (see system ZScan of Menci software) and, therefore, the production of pairs of pictures (digital) stereoscopic. In the case of using the technique of stereophotogrammetry, prepares the necessary project of recovery, are cataloged individual frames or stereo pairs, we proceed to the identification of control points and their documentation. Systematically proceed to duplicate the images to keep a copy on file;

phase IV: Electronic detection. The electronic survey was made on the basis of a draft drawn up beforehand in order both to minimize the areas not scanned, both as to achieve the greater homogeneity (in relation to the distance) in the scanning density. The project may provide for the realization of specific scans necessary to the detection of detail. Of this survey will be kept all the documentation, all point clouds and photographs that will be performed in accompaniment to the clouds;

phase V: Survey of completion. By this term we refer to the acquisition of those series of photographs necessary for the use of additional software that allows to build the missing parts of surfaces (gaps) in the models or in stereo-electronic scans, as in the case of the columns of the cloister of Villa Rufolo. This is a particularly delicate phase whose characteristics and manner of execution should already be outlined as a result of the inspection general of the places;

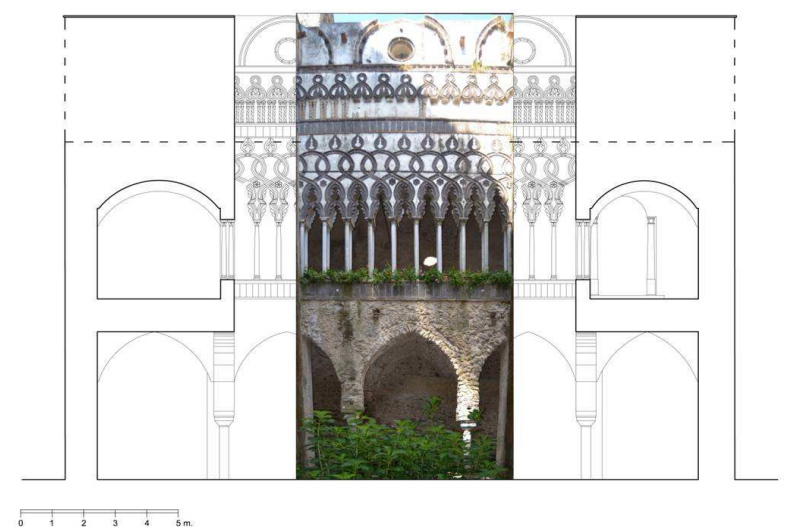

Figure 6. Section of the courtyard with orthophotos Wall Arab 


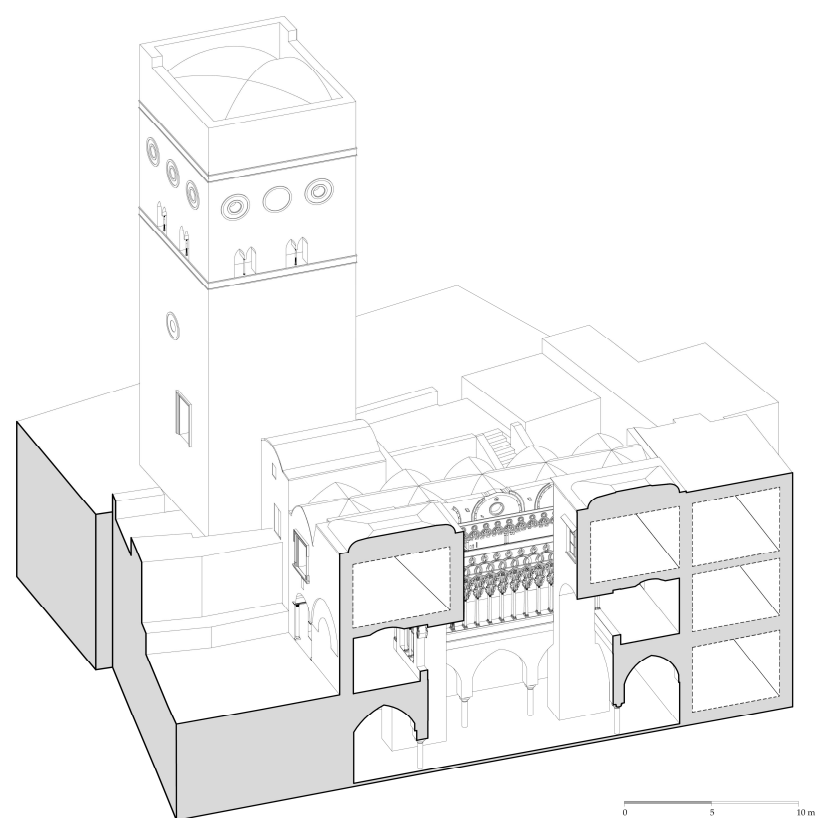

Figure 7. Axonometric section from digital model

Phase VI: representations of two-and three-dimensional, 3D modeling. This phase covers all operations return and use the data acquired during the survey. It is important to acquire the three-dimensional models as well as various render, whereas only models allow further manipulation is both metric checks.

Phase VII: Archiving of all data prepared for the use of various techniques, and the data acquired and processed. The object of this phase is to allow, in later times, the continuation of relief - with a different goal or insights - without having to start over.

It is also important to take caution to duplicate the file and store it in separate locations. The availability of software that automatically manipulate point clouds creating surface meshes and producing a three-dimensional model, generates more in the incorrect belief that that model is the logical result of the survey. In this field, the information is significantly incomplete, is never reported, indeed, that, proceeding to meshing with two different software - based on the individual, different algorithms - the result will probably be different. This would suffice to signify that a model of mesh surfaces tract from the point cloud is still a useful operation (for example, for verification of the existence of any "gaps", etc.) but that the product model corresponds to only one of the surfaces mathematically compatible with the points acquired in the scan; one of those possible because, using a different software, the result could be different.

The research, however, had a further result is not closely related to its initial objectives. The relief of the building organism has confirmed - if that were necessary - the value of critical knowledge, its realization has led to a greater understanding of the work in figurative and compositional aspects hitherto unexplored; based on fact, survey data and refunds and processing consequential reconsideration of the tormented - the earthquake in the early eighteenth century, the wartime damage of the twentieth century and the subsequent partial reconstruction - which helped to determine the current structure, and critical analysis of the current geometric configuration with

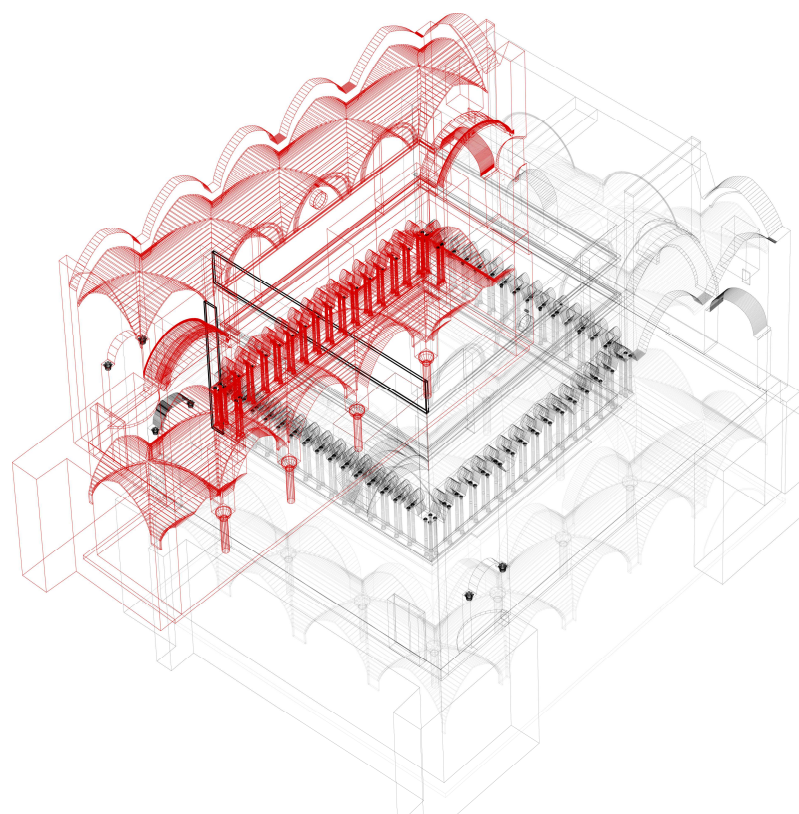

Figure 8 . The digital model of the virtual reconstruction

the interpretation of its surviving original characters, a bibliographic research and documentary sources (though not indepth) - it was possible to develop a hypothetical reconstruction of its original virtual that returns the full dignity even in comparison with other models of architectures Islamic influence present, to a particularly widespread in Sicily.

The Villa Rufolo is presented as an architectural structure that, in the lower level has been, in the past centuries, greatly manipulated with the realization of the mighty wall structure to support what the old building had survived the earthquakes of the early 1713 (Giovannini P., 2000). It is known that, as a result of those seismic events, had collapsed the western wing of the factory and that, under reconstruction, had given up his full restoration also deciding the burial of the lower part of the lower floor, this sequence of events could also provide the reason for the architectural forms that are observed in low relief on the lower floor, on the west wall of the cloister and that hint at a series of three arches of which the two lateral partially hidden by walls erected to the garrison. We can not ignore, however, the high capitals that are read on the outer wall west who could have provided the grafting of arches and vaults of another ambulatory been destroyed. Morphological analysis of the small structure, its importance, the analysis of its various parts (although plenty rebuilt as a result of the war) have also suggested to elaborate - in relation to the actual extent of wall columns of the ambulatory and primary other conserved elements on adjacent walls - a hypothesis about the configuration of the virtual reconstruction of the ancient cloister, of course different from today in which the delicacy of the elements that bear witness to the Arab influence is "forced" by building structures made for their support in the eighteenth century. The reconstructive hypothesis - to feel absolutely wide maximum - the ancient cloister was built in the form of threedimensional model and return plano-altimetric, it is based on the following assumptions:

- covers the walkways to the lower input level (the top) of the cloister, should be regarded, by their shape, coeval with the interventions of strengthening walls of the eighteenth century, as a result or conduct originating in ambulatory children we can 


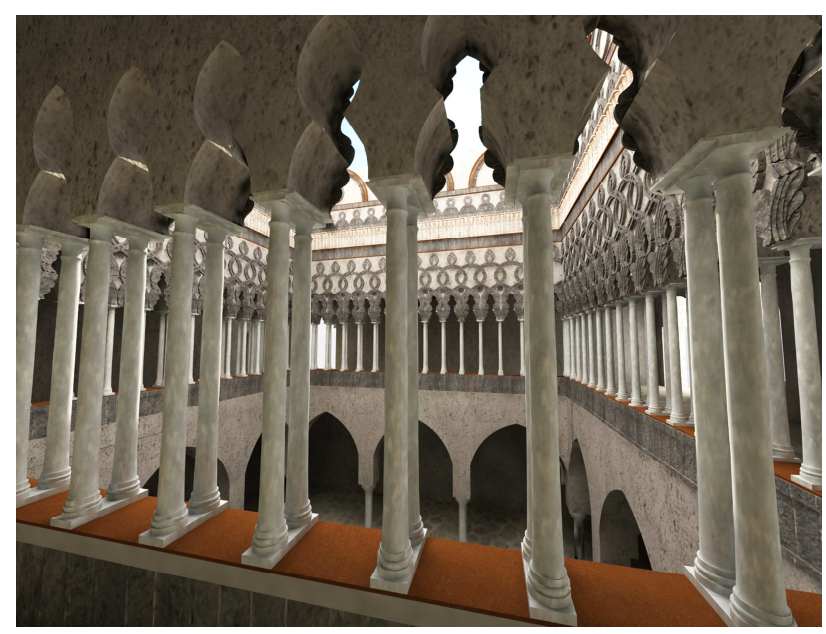

Figure 10. Rendering of the virtual model reconstruction

assume similar in forms and height, greater than that of the ambulatory (as is recorded at the lower level);

- also along the ambulatory minors reiterating the upper level (input), walls with double columns today as we read in the larger one, and as can be seen from the traces that remain.

On the basis of the findings, the hypothesis, with respect to current returns-on-one situation of the places of breath in the performance space: this hypothesis refers to the original configuration of the two levels of the cloister limited to the performance of its ambulatory order to reconstruct the morphology and characteristics of the reservoir (the airiness of the system, the lightness of architectural textures, the lighting conditions in general) have not, in fact, found sufficient evidence to reconstruct neither internal nor in the articulation Its volume of the wing that was to accompany the fourth side of the ambulatory, to the west. The wall columns regains its original performance is almost double than what is currently visible, a hypothetical reconstruction also affects the other two walls (orthogonal to the first), in line with the surviving elements of the ancient arches interlaced, and is certainly more appropriate to importance of family Rufolo, with an overall configuration of space and forms more consistent than episodes (such as Monreale, Sicily and that of the facade of the Duomo di Amalfi) received us somewhat intact.

Having checked the system and the central square of the reservoir constant width of ambulatory survivors, having established the analogy of the forms of arches supported by columns still exist in the ambulatory children with those stored the ambulatory main, we proceeded as follows: on the ground of Input: observing the partition wall with columns visible today (from the balcony to the west) and assuming the removal of the walls that hide the extreme parts, was natural to assume that the decorative part of the outer wall above the double columns are complete according to a strict geometric criterion also evidenced by the already visible small facade. Moreover, the modules with four columns that are observed at the ends of the wall columns in the Main Gallery are certainly a type of corner solution to be found, though in a different form, in other cloisters of the period over which an appropriate solution under the ' static aspect in replacement of a pillar which, occupying the thickness of each of the two facades in their intersection, would have to collect the resultant thrust of three vaults for each corner; with this function, the module has been repeated in the virtual model in the four intersection of the outer walls of the cloister. For the fourth side, the virtual reconstruction involved - as already mentioned - only the ambulatory, reiterating the

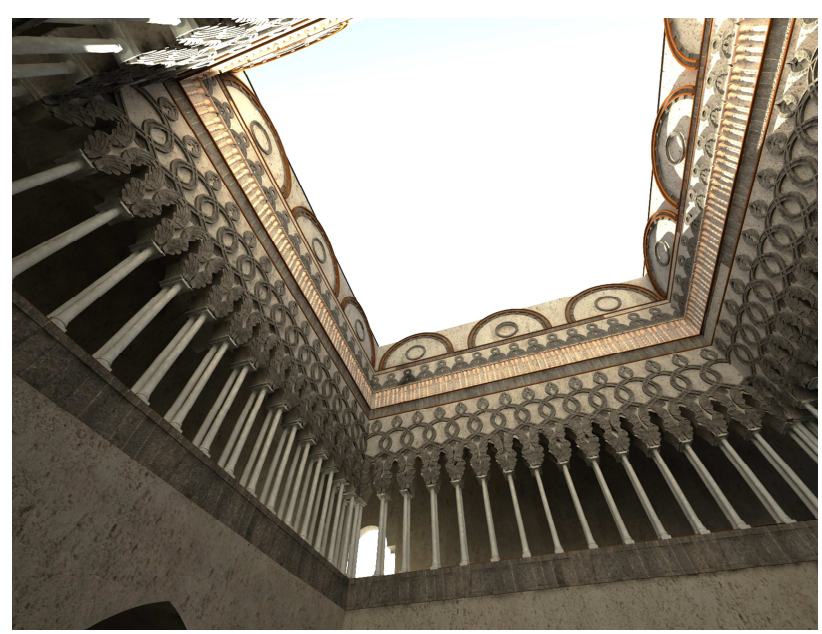

Figure 10. Rendering of the virtual model reconstruction

same modules as the opposite of the ambulatory and replicating the sequence of coupled columns and arches overlying intertwined. In the virtual reconstruction, of course, for all ambulatory was adopted the same type of roofing vaults. For the lower level, virtually obliterating the walls nineteenth century, they came back naturally in view of the pointed arches on columns with which the vaults of the three ambulatory volume ahead of the cloister, as for the higher level, for the side Western was made a virtual reconstruction of replicating the ambulatory opposite, with its vaulted ceilings set on the wall of the sphere and four columns towards the reservoir.

The virtual reconstruction described so far has also been supplemented by decorative elements that characterize the exterior walls above the twin columns, I refer to the elements that emphasize the pseudo-floral arches interlaced, semi-circular moldings above it, and the other elements of cooked that punctuate the high end that ends with the external shape of the extrados of the time coverage.

At the conclusion of the search, and according to experiments carried out, with reference to the initial question concerning the integration of various techniques of survey and related problems, one can observe the following:

- traceability of all the current techniques of detecting instrumental in the electron emission makes as it were homogeneous;

- the widespread use of computers for all activities refund (including data acquired with non-instrumental techniques) results, with the digitization, the "homogenization" of all the information acquired and used (even of the measurements taken with a tape measure) .

In conclusion, the research has highlighted the ability to be able, in the process of documentation and preservation of any architectural structure is preparing us to study not only the most modern detection techniques as well as those that are historical for their integration received by the overall knowledge and global building under study.

\section{REFERENCES}

Barba, S., 2008. Tecniche digitali per il rilievo di contatto. Ed. CUES. 
Cardone, V., Giordano, M., 2011. Computer vision and Photo Scanning. The online journal computer science and information technology. Vol. 1 - No. 3. Salerno, pp. 78-82.

Giovannini, P., 2000. La Galleria inferiore del "cortile moresco" di Villa Rufolo a Ravello. Impiego dell'endoscopia, studio dell'apparecchio murario e ipotesi sulle fasi di restauro in PEDUTO Paolo e WIDEMANN François (a cura di), L'ambiente culturale a Ravello nel Medioevo. Il caso della Famiglia Rufolo. Edipuglia, pp. 4971.

Iannizzaro, V., 2003. Considerazioni sul rilievo per l'architettura. Ed. CUES;

Iannizzaro, V., Barba, S., Fiorillo, F., 2009. Il laser scanner nel rilievo per il consolidamento strutturale.

Messina, B., 2012. Architettura e forme in Costa d'Amalfi dal segno al disegno di un paesaggio costruito. Ed. CUES;

Panofsky, E., 1962. Il significato nelle arti visive, Einaudi, Milano. 